\title{
NLRP3 inflammasome activation modulates exosomal RNA content and inhibits inflammatory responses in recipient cells
}

\author{
Wojciech Cypryk ${ }^{1}$, Sampsa Matikainen ${ }^{2}$ \\ ${ }^{1}$ Centre of Molecular and Macromolecular Studies, Polish Academy of Sciences, Lodz, Poland; ${ }^{2}$ Helsinki Rheumatic Disease and Inflammation \\ Research Group, Translational Immunology Research Program, University of Helsinki, Helsinki University Clinicum, Helsinki, Finland \\ Correspondence to: Wojciech Cypryk. Centre of Molecular and Macromolecular Studies, Polish Academy of Sciences, 90-363 Lodz, Poland. \\ Email: wcypryk@cbmm.lodz.pl; Sampsa Matikainen. Helsinki Rheumatic Disease and Inflammation Research Group, Translational Immunology \\ Research Program, University of Helsinki, Helsinki University Clinicum, 00290 Helsinki, Finland. Email: sampsa.matikainen@helsinki.fi. \\ Comment on: Budden CF, Gearing LJ, Kaiser R, et al. Inflammasome-induced extracellular vesicles harbour distinct RNA signatures and alter \\ bystander macrophage responses. J Extracell Vesicles 2021;10:e12127.
}

Received: 08 October 2021; Accepted: 08 November 2021; Published: 30 November 2021.

doi: $10.21037 /$ exrna-21-19

View this article at: https://dx.doi.org/10.21037/exrna-21-19

Extracellular vesicles (EV) are nanometer-sized membranebound entities secreted by cells, mediating important intercellular communication in orchestration of immune responses (1). The roles of macrophage-derived $\mathrm{EV}$ have been implicated in inflammatory conditions including cardiovascular diseases, metabolic conditions and microbial infections (2). Inflammation is in part driven by the function of inflammasomes-cytosolic patter recognition receptors of the innate immune system, among them most prominently by NLRP3 inflammasome activated by a wide range of microbial and endogenous ligands (3). Increased secretion of EVs with modified protein and RNA signatures has been recently linked with the function of the inflammasome $(4,5)$. In a recent paper, Budden and colleagues analyze in detail the pattern of $\mathrm{EV}$ secretion regulated by inflammasome activity exerted by treatment of LPS-primed THP1 macrophages with nigericin, a welldescribed canonical inflammasome activator (6). First, they fractionated vesicles by differential centrifugation and size exclusion chromatography (SEC) to obtain preparations of large, intermediate and small EV. Secretion of all vesicle types was markedly enhanced upon nigericin treatment. Importantly, the authors clearly demonstrate that the effect is due to canonical NLRP3 inflammasome activity, as inhibition of caspase- 1 and gasdermin D leads to significant reduction of EV secretion. Interestingly, this dependence was not observed when NLRP3 inflammasome was activated by MSU crystals. In line with this result, it has been previously shown that MSU-induced cell death is NLRP3 independent indicating a potential existence of another receptor for MSU mediating $\mathrm{EV}$ release and cell death $(7,8)$. In conclusion, the results of Budden and co-worker's suggest that release of EVs in response to inflammasome activation is not a passive, pyroptosis-driven event, but is instead highly regulated.

The authors followed their observations with in-depth transcriptomic analysis of the RNA content of the EV secreted during inflammasome activation and found that intermediate (10K) EV differ substantially from small EV in terms of their RNA transcript composition. However, the overall composition of the fractions is similarly modified regardless of type of the inflammasome-activating stimulus.

In an attempt to understand the physiological effects of $\mathrm{EV}$ in inflammatory process, the inflammasomeinduced EV isolated from THP-1 macrophages were incubated with naive THP-1 macrophages to monitor their inflammatory response by transcriptomics. To exclude a possible autocrine inflammatory effect, the authors used NLRP3 KO cells as recipients. While SEC-derived small $\mathrm{EV}$ did not trigger any significant changes in the phenotype of the recipient cells, the $10 \mathrm{~K}$ intermediate $\mathrm{EV}$ turned out to activate the interferon transcriptional program, causing significant upregulation of interferon stimulated genes (ISGs), including Mx2, ISG15 and OAS3. The same effect was observed when primary human macrophages were incubated with the $10 \mathrm{~K} \mathrm{EV}$ pool. These results for the first time demonstrate that inflammatory $\mathrm{EV}$ may be involved in mediating interferon responses. 
In order to identify the mechanism by which inflammatory EV mediate interferon response, a series of experiments was conducted to analyze the possible contribution of well-known signaling pathways resulting in ISG expression. TANK-binding kinase 1 (TBK1) KO cells presented similar pattern of ISG expression upon incubation with inflammatory $\mathrm{EV}$, indicating that induction of the interferon transcriptional program is not a result of primary pattern recognition receptor activation. Similarly, inhibition of STING using H-151 did not diminish the interferon response resulting from contact with inflammatory $\mathrm{EV}$. The possible vesicular transfer of IL- $1 \beta$ was also ruled out, as coincubation with anakinra, a IL-1 receptor antagonist did not inhibit interferon responses. These results suggested that interferon transfer may be a direct cause of upregulation of ISG. This turned out to be true when a soluble decoy type I interferon receptor or heat inactivation completely abrogated the induction of ISGs exerted by EV transfer. Macrophages take up EVs through phagocytosis and EV cargo, including IFN- $\beta$, ends up in endosomes. It is not yet known whether EV-derived IFN- $\beta$ can elicit interferon signature solely from the endosomes in the absence IFN- $\alpha / \beta$ receptor engagement at the plasma membrane. However, the provided data demonstrate a functional IFN- $\beta$ export via EVs during inflammasome activation. In cryopyrinassociated periodic syndrome (CAPS) and neonatal onset multi-system inflammatory disease (NOMID) patients NLRP3 inflammasome is centrally involved in disease pathogenesis. Interestingly, in these diseases upregulation of ISGs is seen, which may be due to inflammasomedependent, $\mathrm{EV}$-mediated IFN- $\beta$ release.

$\mathrm{EV}$-mediated IFN- $\beta$ may have important consequences as IFN- $\beta$ is a known negative regulator of inflammasome responses (9) and being transferred within EV can travel long distances in the bloodstream protected from degradation and modulate inflammatory responses in bystander cells. The authors attempted to verify this hypothesis by preincubation of human primary monocytederived macrophages with small and intermediate EVs before activation of inflammasome by LPS priming and nigericin treatment. Interestingly, when naive cells were pretreated with $10 \mathrm{~K} \mathrm{EVs}$, the inflammasome activation by nigericin resulted in increased IL- $1 \beta$ release, while LPSprimed cells demonstrated reduced IL- $1 \beta$ release after exposure to EVs. No such effect was observed with small $\mathrm{EV}$ preincubation. These somewhat conflicting data suggest biased effect of inflammasome-induced $\mathrm{EV}$ in augmentation of inflammatory responses in bystander cells and will require further investigation.

Together, the work by Budden and colleague explores in detail a recently described phenomenon of inflammasomeinduced EV secretion. By RNA profiling, the authors show that inflammatory activity, regardless of the stimulus by which it was induced, changes the RNA signatures of the secreted EVs. NLRP3 inflammasome is involved in many inflammatory diseases and RNA signature of EVs could be used as a biomarker for NLRP3 inflammasome activity. This RNA signature could be used to select patients that could benefit from an inflammasome targeting therapy.

IFN- $\beta$ has been used in clinical trials to treat severe COVID-19 (10). The use of IFN- $\beta$ has been based on the evidence that IFN- $\beta$ has anti-viral activity against SARS$\mathrm{CoV}-2$ infection. SARS-CoV-2 infection is also known to activate NLRP3 inflammasome and NLRP3 centrally contributes to disease pathogenesis. It will be interesting to see whether SARS-CoV-2 infection induces EVs that contain IFN- $\beta$ and whether this phenomenon contributes to antiviral response against SARS-CoV-2 infection.

\section{Acknowledgments}

Funding: This work was supported by the Academy of Finland (decision number 322638 to SM) and by the National Science Centre, Poland (grant 2018/28/C/ NZ6/00069 to WC).

\section{Footnote}

Provenance and Peer Review: This article was commissioned by the editorial office, $E x R N A$. The article has undergone external peer review.

Conflicts of Interest: Both authors have completed the ICMJE uniform disclosure form (available at https://dx.doi. org/10.21037/exrna-21-19). The authors have no conflicts of interest to declare.

Ethical Statement: The authors are accountable for all aspects of the work in ensuring that questions related to the accuracy or integrity of any part of the work are appropriately investigated and resolved.

Open Access Statement: This is an Open Access article distributed in accordance with the Creative Commons Attribution-NonCommercial-NoDerivs 4.0 International License (CC BY-NC-ND 4.0), which permits the non- 
commercial replication and distribution of the article with the strict proviso that no changes or edits are made and the original work is properly cited (including links to both the formal publication through the relevant DOI and the license). See: https://creativecommons.org/licenses/by-nc-nd/4.0/.

\section{References}

1. Zhou X, Xie F, Wang L, et al. The function and clinical application of extracellular vesicles in innate immune regulation. Cell Mol Immunol 2020;17:323-34.

2. Wang Y, Zhao M, Liu S, et al. Macrophage-derived extracellular vesicles: diverse mediators of pathology and therapeutics in multiple diseases. Cell Death Dis 2020;11:924.

3. Yang Y, Wang H, Kouadir M, et al. Recent advances in the mechanisms of NLRP3 inflammasome activation and its inhibitors. Cell Death Dis 2019;10:128.

4. Cypryk W, Nyman TA, Matikainen S. From Inflammasome to Exosome-Does Extracellular Vesicle Secretion Constitute an Inflammasome-Dependent Immune Response? Front Immunol 2018;9:2188.

5. Wozniak AL, Adams A, King KE, et al. The RNA

doi: 10.21037/exrna-21-19

Cite this article as: Cypryk W, Matikainen S. NLRP3 inflammasome activation modulates exosomal RNA content and inhibits inflammatory responses in recipient cells. ExRNA 2021;3:8. binding protein FMR1 controls selective exosomal miRNA cargo loading during inflammation. J Cell Biol 2020;219:e201912074.

6. Budden CF, Gearing LJ, Kaiser R, et al. Inflammasomeinduced extracellular vesicles harbour distinct RNA signatures and alter bystander macrophage responses. J Extracell Vesicles 2021;10:e12127.

7. Chuang JP, Kao CY, Lee JC, et al. EPS8 regulates an NLRP3 inflammasome-independent caspase-1 activation pathway in monosodium urate crystal-treated RAW264.7 macrophages. Biochem Biophys Res Commun 2020;530:487-93.

8. Orlowski GM, Sharma S, Colbert JD, et al. Frontline Science: Multiple cathepsins promote inflammasomeindependent, particle-induced cell death during NLRP3dependent IL-1 $\beta$ activation. J Leukoc Biol 2017;102:7-17.

9. Guarda G, Braun M, Staehli F, et al. Type I interferon inhibits interleukin-1 production and inflammasome activation. Immunity 2011;34:213-23.

10. Alavi Darazam I, Shokouhi S, Pourhoseingholi MA, et al. Role of interferon therapy in severe COVID-19: the COVIFERON randomized controlled trial. Sci Rep 2021;11:8059. 